\title{
Improving QPF by blending techniques at the Meteorological Service of Catalonia
}

\author{
A. Atencia ${ }^{1,2}$, T. Rigo ${ }^{1}$, A. Sairouni ${ }^{1}$, J. Moré ${ }^{1}$, J. Bech ${ }^{1}$, E. Vilaclara ${ }^{1}$, J. Cunillera ${ }^{1}$, M. C. Llasat ${ }^{2}$, and L. Garrote ${ }^{3}$ \\ ${ }^{1}$ Meteorological Service of Catalonia, Spain \\ ${ }^{2}$ Department of Astronomy and Meteorology, Faculty of Physics, University of Barcelona, Spain \\ ${ }^{3}$ Department of Hydraulic and Energy Engineering, Technical University of Madrid, Spain
}

Received: 26 December 2009 - Revised: 12 April 2010 - Accepted: 17 June 2010 - Published: 7 July 2010

\begin{abstract}
The current operational very short-term and shortterm quantitative precipitation forecast $(\mathrm{QPF})$ at the Meteorological Service of Catalonia (SMC) is made by three different methodologies: Advection of the radar reflectivity field (ADV), Identification, tracking and forecasting of convective structures (CST) and numerical weather prediction (NWP) models using observational data assimilation (radar, satellite, etc.). These precipitation forecasts have different characteristics, lead time and spatial resolutions. The objective of this study is to combine these methods in order to obtain a single and optimized QPF at each lead time. This combination (blending) of the radar forecast (ADV and CST) and precipitation forecast from NWP model is carried out by means of different methodologies according to the prediction horizon. Firstly, in order to take advantage of the rainfall location and intensity from radar observations, a phase correction technique is applied to the NWP output to derive an additional corrected forecast (MCO). To select the best precipitation estimation in the first and second hour $(t+1 \mathrm{~h}$ and $t+2 \mathrm{~h})$, the information from radar advection (ADV) and the corrected outputs from the model (MCO) are mixed by using different weights, which vary dynamically, according to indexes that quantify the quality of these predictions. This procedure has the ability to integrate the skill of rainfall location and patterns that are given by the advection of radar reflectivity field with the capacity of generating new precipitation areas from the NWP models. From the third hour $(t+3 \mathrm{~h})$, as radar-based forecasting has generally low skills, only the quantitative precipitation forecast from model is used. This blending of different sources of prediction is verified for different types of
\end{abstract}

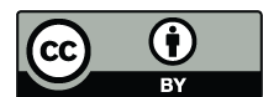

Correspondence to: A. Atencia (aatencia@meteo.cat) episodes (convective, moderately convective and stratiform) to obtain a robust methodology for implementing it in an operational and dynamic way.

\section{Introduction}

Blending is the merging of extrapolation radar-based schemes with NWP model predictions. The first approaches in blending nowcasts were introduced by Golding (1998) in Nimrod system and by Pierce et al. (2001) in Gandolf. In both systems blending is achieved in physical space and the weight given to the extrapolation component takes the form of a fixed exponential decay with time. Later works (Venugopal et al., 1999; Germann and Zawadzki, 2002) have shown that predictability of rainfall structures has a scale-dependence based on dynamic scaling processes. In the Short-Term Ensemble Prediction System (STEPS, see Bowler et al., 2006) the merging of the extrapolation and NWP component forecasts is performed in a scale-dependent way using several levels on cascade processes. Other authors (Lin et al., 2005) compared the precipitation forecast skill of a radar-based nowcast scheme (Germann and Zawadzki, 2002) and that obtained from a numerical model (Côté et al., 1998). They attempt to optimize the statistical blending of model and radar products by discovering the best lead-time to change from one product to the other in an operational setting. This approach is further addressed by Ebert and Seed (2004) who note the limitations of such methods. As a response to these limitations, there has been a recent trend away from simple deterministic forecasts of precipitation location and quantity toward offering probabilistic forecasts that include a measure of uncertainty. Bowler et al.

Published by Copernicus Publications on behalf of the European Geosciences Union. 
(2006) have merged extrapolation forecasts with downscaled NWP forecasts. They combine spatial cascades of QPF fields generated by an extrapolation scheme, a NWP model downscaled precipitation cascade and a noise field to produce a blended, probabilistic QPF. This approach accounts for not only the uncertainty in motion that has been attempted before (e.g. Schmid et al., 2002), but also the uncertainty in the development of the precipitation field. Pierce et al. (2005), as well as Fox et al. (2005), attempt to determine more explicit measures of uncertainty by running multiple realizations of their nowcast schemes.

All the NWP models used in these blending approaches are both downscaled and applied along vast regions. However, it is known that position errors are observed frequently in the forecast models when comparing with observation. These errors have several causes as some researchers have found out. For instance, Mariano (1990) shows the use of different initial condition data and model resolution leads to position errors due to approximations of governing equations. The objective analysis, retrieval, or assimilation system must then remove the incorrectly forecasted disturbances and rebuild them in the proper location. That is a difficult task when the features are temporally or spatially intermittent and an accurate estimate of the background error is lacking at such scales. The scarcity and incompleteness of data at lower meso-scales add difficulty to the analysis. For this reason, meso- $\beta$ and meso- $\gamma$ scale processes (from Thunis and Bornstein, 1996) such as thunderstorms, squall-lines or so on, are generally not well positioned or reproduced. A sensitivity study of precipitation data conducted by Jones and Macpherson (1997) shows that position errors lead to significant degradation of forecasts with assimilation. Brewster (2003a) argues that the presence of infrequent spatiotemporal features with a lack of background error estimates, and incomplete data at small scales makes this problem hard to solve and proposes a shift-vector modification to the model field to correct phase errors. The correction of forecast rainfall field by comparing with observation are carried out by Lee et al. (2009) who shows a similar quality between phasecorrected NWP model and radar-based nowcasting.

This work is validated with 7 case studies with different features exposed in Sect. 2. In this section the current operational sources of rainfall forecast are exposed too. The new techniques developed to improve the first $6 \mathrm{~h}$ of hourly accumulated rainfall forecast are described in Sect. 3. Firstly, a modification of the shift vector technique for phasecorrecting is applied. After that, several indexes are tested for blending both forecasts. A new procedure to construct the blending is developed by decomposing the model into new rainfall areas and advection ones. The results obtained are presented in Sect. 4. Finally, the main conclusions of this work are presented as summary of this paper.

\section{Data sources and case studies}

\subsection{Quantitative Precipitation Estimation (QPE) from radar data}

The Meteorological Service of Catalonia owns a radar network (XRAD) that covers an area of $53000 \mathrm{~km}^{2}$ (Catalonia, NE Spain, and surrounding area). This network is made up of four C-band Doppler radars. The most important characteristics of the composed Constant Altitude Plan Position (CAPPI) imagery used in the present work are the spatial resolution $\left(2 \times 2 \mathrm{~km}^{2}\right.$ each pixel), time resolution $(6 \mathrm{~min})$ and vertical resolution $(1 \mathrm{~km})$ from $1 \mathrm{~km}$ to $10 \mathrm{~km}$ of altitude $(10$ levels). The maximum reflectivity value is selected at each pixel during the composition process. The CAPPI is generated by means of the Sigmet IRIS software which is based on linear interpolation in range to the selected heights on Spherical coordinates with earth curvature correction to preserve data quality. On the other hand, the 1-h accumulated rainfall field has been generated by the Hydrometeorological Integrated Forecasting Tool (EHIMI) (Sánchez-Diezma et al., 2002), a software package designed to correct radar observations in real-time. The main corrections currently implemented in this system (Bech et al., 2005) can be summarized as:

- Correction of radar rainfall measurement stability using mountain returns (Sempere-Torres et al., 2003). This procedure provides a general factor of correction by comparing the distribution average and current ground clutter echo maps.

- Interpolation of blocked azimuths.

- Orographic corrections, which involve radar pointing errors and screening effects (Delrieu et al., 1995). Ground clutter identification and substitution (SánchezDiezma et al., 2001) by using a precipitation type based substitution technique and Doppler information. Removal of contamination due to radar secondary lobes (Bellon and Kilambi, 1999).

- Removal of residual speckles not related to the precipitation (Berenguer et al., 2006). The events examined were not affected by intense super-refraction according to the approach proposed by Bech et al. (2007).

Once these corrections have been applied, the corrected reflectivity CAPPI field is used to obtain hourly precipitation accumulations using the Marshall and Palmer (1948) Z-R relationship. The resulting hourly rainfall field is a Cartesian product, which has a $1 \times 1 \mathrm{~km}^{2}$ spatial resolution.

\subsection{Rain gauge network data}

The ground rain-gauge data used to select the case studies in this article was provided by the XEMA network (Prohom 
Table 1. Rainfall amount and intensity for the seven study events from radar data and raingauge data.

\begin{tabular}{lcccc}
\hline & \multicolumn{2}{c}{$\begin{array}{c}\text { Max. daily rainfall } \\
\text { amount }(\mathrm{mm})\end{array}$} & \multicolumn{2}{c}{$\begin{array}{c}\text { Max. hourly rainfall } \\
\text { intensity }(\mathrm{mm} / \mathrm{h})\end{array}$} \\
\hline Data & Raingauge & Radar & Raingauge & Radar \\
\hline 3 Oct 2008 & 38.0 & 51.3 & 28.7 & 78.2 \\
16 Apr 2009 & 25.4 & 34.7 & 7.6 & 19.6 \\
30 May 2009 & 34.6 & 81.7 & 20.7 & 59.7 \\
4-6 Jun 2009 & 60.8 & 54.2 & 24.0 & 41.4 \\
19 Jun 2009 & 70.4 & 68.9 & 28.5 & 30.9 \\
24-26 Jun 2009 & 58.3 & 106.1 & 37.6 & 65.2 \\
14 Jul 2009 & 34.7 & 27.5 & 34.7 & 21.4 \\
\hline
\end{tabular}

and Herrero, 2009) and it is supported by Catalan Meteorological Service. It is composed of 158 rain-gauges and it covers the whole Catalonian area (around $32114 \mathrm{~km}^{2}$ ). This network records the precipitation at different temporal intervals. There are 47 stations which accumulate the precipitation every $30 \mathrm{~min}$ and the remaining 111 stations have onehour temporal resolution. Merging both different time resolution networks a new one is obtained with a mean density of near 1 gauge every $200 \mathrm{~km}^{2}$ and one-hour temporal resolution.

\subsection{Case studies}

During spring 2009 and the beginning of summer of 2009 six events were selected by recorded daily rainfall amounts over $25 \mathrm{~mm}$, at least in one point, in both precipitation estimation networks (Radar and rain-gauges). Another previous case study used in this article is the 3 October 2008 event. The highest rainfall amounts of those cases are detailed in Table 1. Genesis and properties of these case studies are widely varied. There is only a stratiform case on 16 April 2009 with $34.7 \mathrm{~mm}$ daily rainfall recorded and rain-gauge intensities of $8 \mathrm{~mm} / \mathrm{h}$. On the other hand, other convective events presented intensities up to $40 \mathrm{~mm} / \mathrm{h}$ in rain gauge and near $80 \mathrm{~mm} / \mathrm{h}$ in radar and rainfall amounts accumulated of more than $100 \mathrm{~mm}$ in $24 \mathrm{~h}$. Different type of events are used in this study to obtain a methodology that could be applied in both stratiform or convective rainfall events.

\subsection{Quantitative precipitation forecast}

The current operational very short-term and short-term QPF at the Meteorological Service of Catalonia is made by three different methodologies:

1. Advection of the radar reflectivity field (field-oriented approach).

2. Identification, tracking and forecasting of convective structures (objected-oriented approach).
Table 2. Configuration of different simulations of MM5 model: Initial conditions (IC), Lateral Boundary Conditions (LBC), and Convection (CONV), Microphysics (MICRO) schemes.

\begin{tabular}{ccccc}
\hline Domains & NX.NY.NZ & IC/LBC & CONV & MICRO \\
\hline $36 \mathrm{~km}$ & $102 \times 94 \times 26$ & ECMWF/GFS & Grell & Schultz \\
$12 \mathrm{~km}$ & $70 \times 70 \times 30$ & MM5-36 km & Grell & Schultz \\
\hline
\end{tabular}

3. Numerical weather prediction models using observational data assimilation (radar, satellite, etc.).

The advection of the radar reflectivity (ADV, hereinafter) field is a modification of the S-PROG technique (Seed, 2003). This modification is based on the advection of the weather radar reflectivity fields considering the motion field, which is derived with an algorithm based on tracking radar echoes by cross-correlation (Berenguer et al., 2005).

The identification, tracking and forecasting of convective structures (CST, hereinafter) are based on the storm cell identification and tracking algorithm (SCIT) developed by Johnson et al. (1998). This SCIT algorithm is customized by applying different reflectivity thresholds in order to identify convective cell contours (2-D and 3-D structures) and centroids including characteristics such as area extension and echo top heights (Rigo and Llasat, 2004, 2007). The tracking and 1-h nowcasting of the 3-D structures is made considering cross-correlation between consecutive images and also NWP-model derived mid-level winds $(700 \mathrm{hPa})$. Moreover, the evolution stage of convective cells (initiation, maturity and dissipation) in the 3-D product is also estimated and forecasted.

The NWP model selected is the MM5 model, a nonhydrostatic primitive equation model using terrain following coordinates (Grell et al., 1994). In this model, the atmospheric conditions were forced with initial and boundary conditions from the European Centre for Medium range Weather Forecast (ECMWF). In this work two simulations are performed using two domains with horizontal resolutions of 36 and $12 \mathrm{~km}$. The large domain covers SW Europe (Table 2); the nested domain has a grid of $12 \mathrm{~km}$ and covers Catalonia (Table 2).

For warm initialization in the MM5, 4DDA grid analysis nudging is used. The nudging is based on the simple idea of Newtonian relaxation that consists in the addition of a term proportional to the difference between the calculated meteorological variables from the model and the observational values in the right part of dynamical equations of the model. A 3-h preforecast analysis nudging period is used. These analysis are generated from the Local Analysis and Prediction System (LAPS). LAPS is a meteorological assimilation tool that combines all available data sources (surface observations, radar, satellite, sounding and aircraft) to generate a coherent three-dimensional representation of atmospheric features 


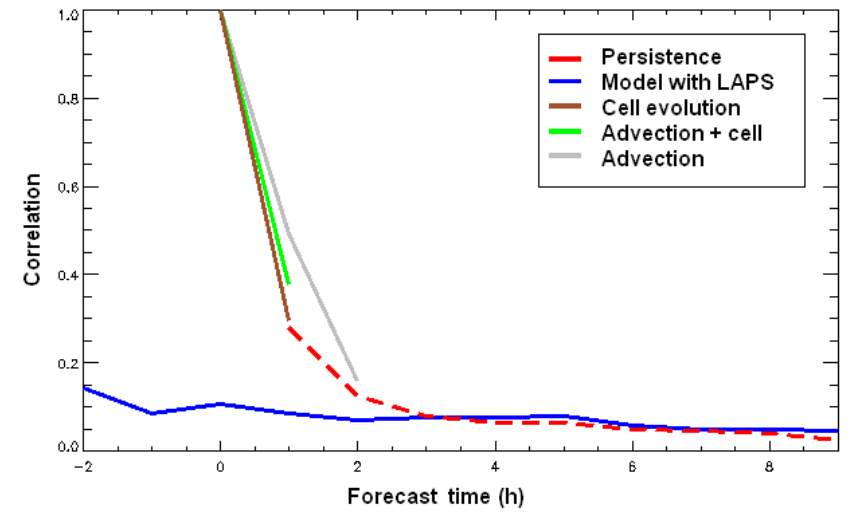

Fig. 1. Correlation of all the current operational forecasts running in the SMC.

and processes with a time interval of an hour (McGinley and Smart, 2001; Albers et al., 1996; Schultz and Albers, 2001).

\subsection{Common grid}

The used methodologies have different spatial resolution and geographical projection. The radar-based cell evolution forecasting methodology has a spatial resolution of $2 \times 2 \mathrm{~km}^{2}$ in a Mercator grid of $215 \times 158$ pixels. On the other hand, the meteorological model has $12 \times 12 \mathrm{~km}^{2}$ horizontal resolution and uses an Stereographic Polar projection. The observation field previously described and the advection of reflectivity field have $1 \times 1 \mathrm{~km}^{2}$ horizontal resolution with Universal Transverse Mercator projection. To easily compare and blend these different rainfall fields in different grids a common grid has been selected. The radar-based cell evolution nowcasting grid is chosen as the common grid. Therefore, advection, model and observation data have to be transformed. A mean between nearest neighbors is applied to upscale the observation and advection to the common grid. The interpolation of the NWP model field to the common grid of $2 \times 2 \mathrm{~km}^{2}$ is carried out by cubic spline interpolation. This simple interpolation method is necessary to allow the comparison and blending. Even though the grid resolution of the NWP is increased, the real resolution of the NWP rainfall field has not changed. So, it should be noted that this interpolation causes a part of comparison error. Figure 1 shows the errors from comparing radar observation to the different forecasts in the common grid.

\section{Methodology}

The aim of the present work is to obtain a single and optimized QPF at each lead time. Two consecutive procedures are developed to address this objective. Firstly, a model correction is applied to reduce the NWP errors due to positioning and shape-pattern of precipitation structures. Once this objective is achieved by applying a shift-vector correction, the blending technique between the model corrected forecast and radar-based nowcast is developed. Two merging methodologies are proposed. The first technique is based on previous bibliography methodologies, but different indexes to compute the weights are tested. The second and original technique developed in this article introduces spatial dependence of weights as distance function to rainfall structures.

\subsection{Model correction}

The NWP models solve the primitive equations to obtain meteorological fields physically coherent. The introduction of observational assimilation improves the initial conditions. However, this fact does not ensure that rainfall output fields from the model reproduce the reflectivity field from the radar assimilated into the model. For this reason an ulterior correction to the rainfall field of the model is applied. The methodology proposed is based on a semi-lagrangian advection of the precipitation field by a decomposed time-dependent shiftvector. This modification is composed of five already existing techniques:

1. Scale decomposition by Discrete Cosine Transformation (DCT) (Denis et al., 2002).

2. Shift-vector search for each scale (Brewster, 2003a).

3. Future shift-vector fields are computed by temporal extrapolation of three previous hour phase error fields (Lee et al., 2009).

4. Semi-lagrangian advection of precipitation structures (Staniforth and Côté, 1991).

5. Use of Gaussian spreading with a radius of influence proportional to the length of the displacement vector (Germann and Zawadzki, 2002).

The shift-vector is a displacement vector that modifies the rainfall field from the model to reduce differences between model predictions and observations. To obtain this vector Brewster (2003b) divided the whole domain into several different size test areas. In the present work, a similar procedure is applied but a scale-decomposition is previously carried out. The four scales or test-areas' sizes are presented in Table 3. The larger test areas are related to the errors in the location of the rainfall structures (Fig. 2a) whereas the smaller ones are more connected with the shape errors of the rainfall structures (Fig. 2b). These vectors are computed by the minimization of the following cost function (Eq. 1):

$J=\frac{s\left(|\boldsymbol{\delta} \boldsymbol{x}|, l^{-1}\right)}{N_{\alpha}} \cdot \sum_{i=1}^{N} \frac{\left\{H\left[\overline{\mathbf{F}}\left(\boldsymbol{x}_{i}+\boldsymbol{\delta} \boldsymbol{x}\right)\right]-\mathbf{O}_{i}\right\}^{2}}{\sigma_{i}^{2}}$

where $\mathbf{O}_{i}$ is the rainfall observed and $\overline{\mathbf{F}}\left(\boldsymbol{x}_{i}+\boldsymbol{\delta} \boldsymbol{x}\right)$ is the rainfall output of NWP model at the location $\boldsymbol{x}_{i}$. The displacement vector is represented by $\delta \boldsymbol{x}$. The forecast field $(\overline{\mathbf{F}})$ is 


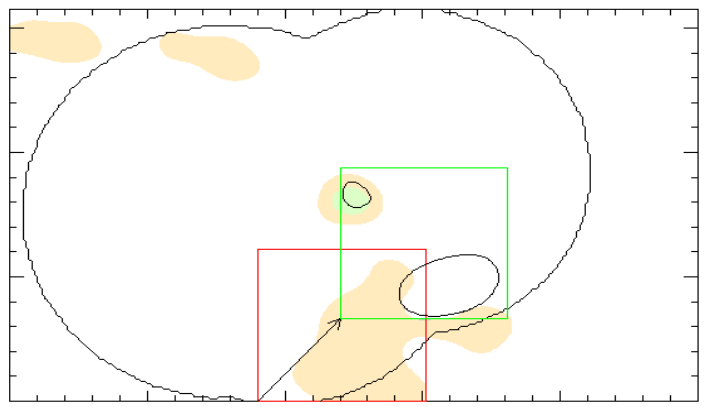

(a) 61 pixels test area size

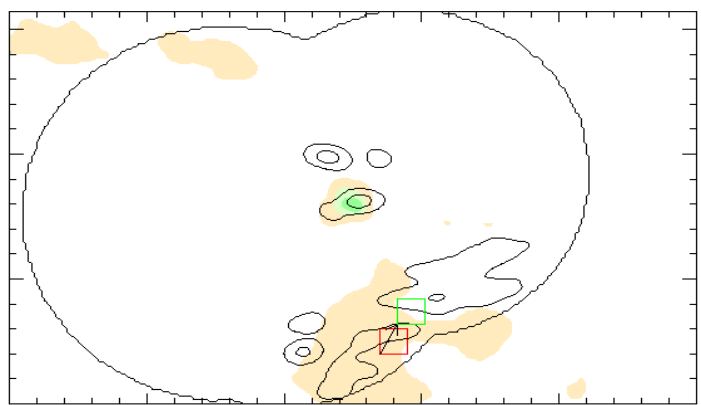

(b) 10 pixels test area size

Fig. 2. Two examples of minimization vector computation for the largest test area (a) and smallest test area (b). The shaded area is the NWP rainfall field and the black contour is the observed rainfall field from the radar. Different shapes are observed in these images due to DCT low-pass filter. The red box is the model test area whereas the green box is the observation test area which minimizes the cost function. Consequently, the displayed vector is shift-vector for this test area.

modified by $(H)$ a Discrete Cosine Transformation (DCT) to a representative scale of the test-volume. This procedure is selected (instead of a Fourier Transformation) because it ensures the capacity of dealing with asymmetry in the field, a common property in rainfall fields. Moreover, a smooth function is applied as cut-off function to avoid the generation of spurious Gibbs waves (Sardeshmukh and Hoskins, 1984). And $\sigma_{i}^{2}$ is the expected observation variance. So, it could be concluded that the right term of Eq. (1) is similar to a root mean square error function for the total number of observations in the region considered or test-volume $(N)$. This function is normalized by the factor $N_{\alpha}$ (Eq. 2):

$N_{\alpha}=\sum_{i=0}^{N} \cdot \alpha_{i}$

where $\alpha$ is a variable that computes the usefulness of these observations following the approach of Brewster (2003a).

The multiplier on the right-hand side of Eq. (1), $s$, is a distance-dependent function that serves as a penalty for similar but distant precipitation structures, i.e. to avoid associating similar structures but that are too distant one from each other. The function used here, from Thiebaux et al. (1990), is the inverse of the second-order autoregressive (SOAR) function (Eq. 3):

$s\left(|\boldsymbol{\delta} \boldsymbol{x}|, l^{-1}\right)=\frac{\exp \left(|\boldsymbol{\delta} \boldsymbol{x}| \cdot l^{-1}\right)}{1+|\boldsymbol{\delta} \boldsymbol{x}| \cdot l^{-1}}$

where $l$ is a length-scale parameter defined as (Eq. 4):

$l=0.5 \sqrt{L_{x}^{2}+L_{y}^{2}}$.

Then, shift-vectors for each test-area are determined by minimizing the previous cost-function. However, nothing ensures coherent shift-vectors between neighbor test-areas. To ensure the continuity of this vector field, some pixels of a test-area overlap another test-area (called overlap pixels in
Table 3. Properties of the four test areas used in the computation of the shift-vectors.

\begin{tabular}{cccc}
\hline $\begin{array}{c}\text { Test area } \\
\text { number }\end{array}$ & $\begin{array}{c}\text { Cut-off scale } \\
\left(\mathrm{km}^{2}\right)\end{array}$ & $\begin{array}{c}\text { Test area } \\
\text { size (pixels) }\end{array}$ & $\begin{array}{c}\text { Overlap pixels } \\
\text { (pixels) }\end{array}$ \\
\hline 1 & 120 & 61 & 31 \\
2 & 70 & 35 & 18 \\
3 & 30 & 16 & 5 \\
4 & 20 & 10 & 5 \\
\hline
\end{tabular}

Table 3) and the shift-vector in these overlap pixels is calculated by averaging the value of each test-area belonged to this overlap area. Once the four scale shift-vector fields are calculated by this methodology, a final modification vector is computed by weighting the four previous ones by means of the cost function value. Therefore, this procedure allows correcting the forecast fields by comparing with observations. However, future shift-vectors fields have to be computed to correct the next hours rainfall forecasts.

To determine these future shift-vectors fields a temporal extrapolation has been used. The extrapolation is carried out by fitting, with a linear regression as a function of time, the three previous hours shift-vectors fields. Minimum coherence between vectors is required. This is set by a minimum threshold of 0.5 of the correlation coefficient. If a vector does not fulfill this requirement, the vector is removed and reconstruct from neighbor vectors. Once the future shift-vector is determined, it is applied by a semi-lagrangian scheme (5). This procedure allows the rotation displacement of the rainfall, and avoids extra dispersion between initial neighbor pixels.

$\boldsymbol{p}_{m}=\delta t \cdot \boldsymbol{U}\left(\boldsymbol{x}_{i}-\boldsymbol{p}_{m}, t_{n}\right)$

where $\boldsymbol{U}$ is the shift-vector at the position $\boldsymbol{x}_{i}$. This scheme is divided up into $N$ steps of length $\delta t$ with $N \cdot \delta t=t_{n}$ and 
$t_{n}$ is the model's time resolution. For each time step, $\boldsymbol{p}_{m}$ is iteratively determined (starting with $\boldsymbol{p}_{m}=0$ ) by Eq. (5) and represents the final displacement vector.

Nevertheless, not all dispersion is avoided. For this reason we use a Gaussian spreading with a radius of influence that is proportional to the length of the displacement vector.

\subsection{Blending technique}

The blending methodology merges the advection technique forecast of the reflectivity field (ADV) with the rainfall field from the numerical weather prediction model. To carry out this procedure, both sources of rainfall forecasts must have the same properties. For this reason, ten reflectivity $(10 \times 6 \mathrm{~m}=1 \mathrm{~h})$ fields are aggregated after applying a Z-R transformation, in such a way that both fields have the same temporal resolution and correspond to the same time period. Moreover, the different spatial resolution and projection is previously matched (see Sect. 2.5). Subsequently, the blending could be carried out by directly merging both fields. However, two techniques are developed in this article. The first one tests the best index and threshold to compute the weights that adjusts the merger. The second one introduces spatial dependence in the weights computation in order to take advantage of the new rainfall structures generated by the model.

\subsubsection{Classical blending}

The different blending techniques developed have used different indexes to compute weights from Golding (1998) to Bowler et al. (2006), all the way to Li and Lai (2004). So, it is needed to test several indexes and thresholds before setting the best blending procedure over the region of analysis. In order to assess this in a suitable way, a standard index $(v)$ is defined. The tested indexes, which are CSI, POD, FAR, bias, TSS, RMSE, \# Pixels and correlation for the thresholds 0.1, $0.2,1,2.5,5$ and $10 \mathrm{~mm}$, are converted into an a-dimensional index that varies between zero for the perfect forecast and infinity for totally mismatching forecasts. The definition of all these indexes and their transformation equation are detailed in Appendix A. Once the standard index is computed, it is introduced into the formulae (6) to obtain the weights for the model $\left(W_{\mathrm{m}}\right)$ and the advection forecast $\left(W_{\mathrm{a}}\right)$ :

$W_{\mathrm{m}}=\frac{v_{\mathrm{a}}}{v_{\mathrm{a}}+v_{\mathrm{m}}} \longrightarrow W_{\mathrm{a}}=1-W_{\mathrm{m}}$.

From these weights, the blending rainfall field is computed as follows:

$\mathbf{R}_{\mathrm{b}}\left(\boldsymbol{x}_{i}, t_{n}\right)=W_{\mathrm{m}} \cdot \mathbf{R}_{\mathrm{m}}\left(\boldsymbol{x}_{i}, t_{n}\right)+W_{\mathrm{a}} \cdot \mathbf{R}_{\mathrm{a}}\left(\boldsymbol{x}_{i}-\boldsymbol{\Delta} \boldsymbol{x}, t_{0}\right)$.

\subsubsection{Spatial blending}

The Eq. (7) computes the rainfall forecast field weighting directly advection and NWP model rainfall field. However, the
NWP field has to be evaluated in more depth. It can be decomposed as follows:

$$
\begin{aligned}
\mathbf{R}_{\mathrm{m}}\left(\boldsymbol{x}_{i}, t_{n}\right)= & \mathbf{R}_{\mathrm{m}}\left(\boldsymbol{x}_{i}-\boldsymbol{\Delta x}, t_{0}\right)+\mathbf{S}_{R}\left(\boldsymbol{x}_{i}\right)+ \\
& +\Delta t \cdot \frac{d \mathbf{R}_{\mathrm{m}}}{d t}+\frac{\Delta t^{2}}{d t} \cdot \frac{d^{2} \mathbf{R}_{\mathrm{m}}}{d t^{2}}+\ldots
\end{aligned}
$$

where the first term is related to the advection of previous rainfall field. The terms in the second line are related to the temporal evolution of existing precipitation structures. Finally, the term $\mathbf{S}_{R}\left(\boldsymbol{x}_{i}\right)$ represents the new precipitation areas.

Looking into the general formulation given by Eq. (7), it has been realized that the source term is weighted by the same index as the advection one. Due to this multiplication, a portion of the new rainfall areas is reduced. To avoid losing information an object-oriented technique is introduced to subtract a spatial-dependent weight. The idea is to split up the advection and evolution term from the source term. For this reason, distance dependent weights to previous existent precipitation structures are computed. The forecast area could be divided into three regions. A first region where precipitation is recorded, a second area called weight variation area and, finally, a third region where only the source term is taken into account. The first region covers the precipitation area existing in the previous time step, the precipitation areas from the advection forecast and $20 \mathrm{~km}$ around these two areas. The weight assigned to this area is computed by the same procedure as the classical scheme. The only source term area is the rest of the domain that is not covered by first and second areas. This area is not weighted, it is only corrected by an intensity bias index. The intensity correction is carried out by comparing previous model forecasting with the final observed rainfall. The weight variation area is defined to ensure the continuity of the rainfall field. The total thickness of this area is $32 \mathrm{~km}$ and the weight fluctuates between the value in the first area (advection area) and the weight in the third area (source-term area). Finally, these weights can be formulated as Eq. (9) as a function of the distance to precipitation structures $\left(d_{p}[x, y]\right)$ :

$W_{\mathrm{m}}\left(d_{p}[x, y]\right)= \begin{cases}W_{\mathrm{m}}^{1} & d_{p}<20 \mathrm{~km} \\ W_{\mathrm{m}}^{2} & 20 \leq d_{p} \leq 52 \mathrm{~km} \\ W_{\mathrm{m}}^{3} & d_{p}>52 \mathrm{~km}\end{cases}$

$W_{\mathrm{m}}^{1}=\frac{v_{\mathrm{a}}}{v_{\mathrm{a}}+v_{\mathrm{m}}} \quad$ inside the advection area

$W_{\mathrm{m}}^{2}=W_{\mathrm{m}}^{1} \cdot\left[\frac{52-d_{p}}{32}\right]+W_{\mathrm{m}}^{3} \cdot\left[1-\frac{52-d_{p}}{32}\right]$

$W_{\mathrm{m}}^{3}=\frac{\sum \cdot O_{i}}{\sum \cdot F_{i}} \quad$ in the whole domain

Equation (10) is the same as Eq. (6), but it is only computed in the new defined advection area. This fact causes 
an increase in the first hour advection weight. The intensity correction is computed by Eq. (12) which is similar to bias index. To take into account a part of the model a minimum value of 0.05 is set to this intensity correction index. This kind of bias is computed over the entire domain due to likely no observation in the source-term area. Moreover, the main objective of this correction is modulating the NWP forecast output. Other techniques are developed with this same objective such as in Casati et al. (2004), Lawson and Hansen (2005) or Casati et al. (2008). Nevertheless, these approaches have to be applied in the model correction to ensure coherency between second and third hour of forecast. So, only an index related to bias is applied to account for the possible error in the new precipitation areas from the model. Finally, Eq. (11) modifies smoothly the weight between $W_{\mathrm{m}}^{1}$ and $W_{\mathrm{m}}^{3}$ along the variation area. In conclusion, the blending Eq. (7) could be written down as Eq. (13) where the spatial dependence of the weights is introduced:

$$
\begin{aligned}
\mathbf{R}_{\mathrm{b}}\left(\boldsymbol{x}_{i}, t_{n}\right) & =W_{\mathrm{a}} \cdot \mathbf{R}_{\mathrm{a}}\left(\boldsymbol{x}_{i}-\boldsymbol{\Delta} \boldsymbol{x}, t_{0}\right)+ \\
& +W_{\mathrm{m}}^{1} \cdot\left(\mathbf{R}_{\mathrm{m}}\left(\boldsymbol{x}_{i}-\boldsymbol{\Delta} \boldsymbol{x}, t_{0}\right)+\Delta t \frac{d \mathbf{R}_{\mathrm{m}}}{d t}+\ldots\right)+ \\
& +W_{\mathrm{m}}^{2} \cdot\left(\mathbf{R}_{\mathrm{m}}\left(\boldsymbol{x}_{i}, t_{n}\right)\right)+ \\
& +W_{\mathrm{m}}^{3} \cdot \mathbf{S}_{R}\left(\boldsymbol{x}_{i}\right)
\end{aligned}
$$

where $W_{\mathrm{a}}$ is now computed as $W_{\mathrm{a}}=1-W_{\mathrm{m}}^{1}$.

\section{Results and discussion}

Taking into account that the main objective is to merge the radar-based nowcasting with the NWP model, the best radarbased nowcasting in the case studies has to be selected. Figure 1 shows three different nowcasting techniques. Both advection and cell evolution forecast are detailed in Sect. 2.4. The third nowcast is made by using the cell evolution information to distinguish between stratiform and convective areas in the advected reflectivity field. However, the results for hourly rainfall accumulations of advection (ADV) are better than either cell evolution (CST) or the merge of them $(\mathrm{ADV}+\mathrm{CST})$. The cell evolution technique would describe in a proper way the growth and decay of the storm and, consequently, it would reproduce the variation of rainfall intensities better than only the advection. Nonetheless, the original storm shape simplification to an ellipse shape is more penalized than intensity mismatch for an hourly accumulation. Advection plus cell evolution rainfall field has a slightly increase of quality, but it has not bet the advection rainfall field. For this reason, advection technique is the selected to blending with the NWP model.

The NWP model has been interpolated by cubic spline to a common grid. This procedure only reduces the grid resolution, but it maintains the real resolution reproduced and simulated by the model. As a result, the comparison between model outputs and radar observations shows a low quality

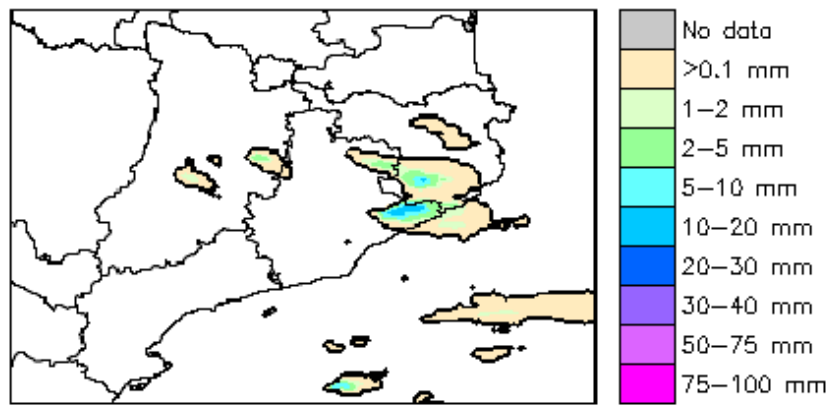

(a) Observation

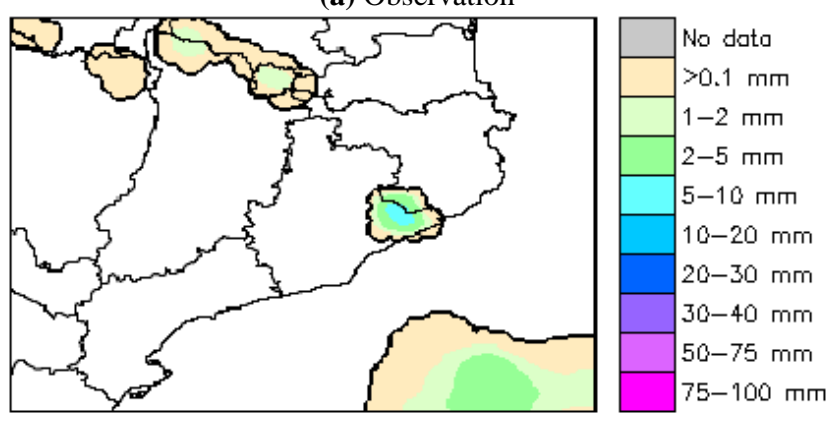

(b) Original model

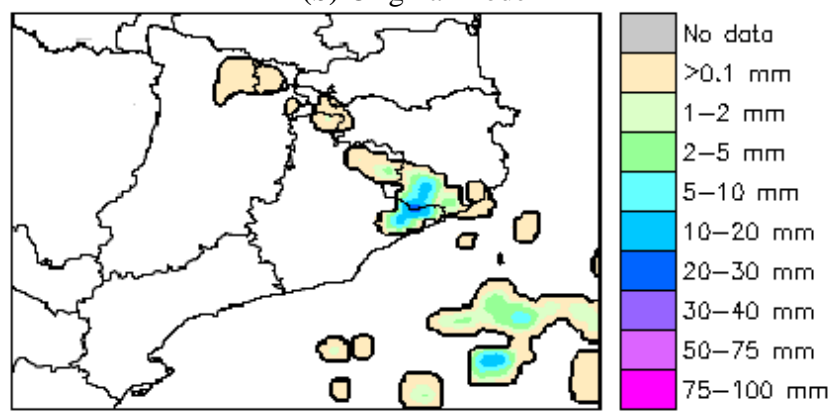

(c) Model corrected

Fig. 3. Example of the model correction procedure for the period 13:00-14:00 UTC $(t+1 \mathrm{~h})$ of 3 October 2008 case.

in both the rainfall position and pattern. Obviously, these errors are not only related with bad positioning or reproduction of the real atmospheric situation, but also with the comparison of rainfall at different scales. For this reason, the persistence bets to the NWP model for the first and second hour (Fig. 4). Because of that, model correction is a necessary previous step to the proposed blending technique and this fact could be observed in Fig. 7 too. Figure 3 shows that this approach reduces the error due to rainfall positioning, but the most noticeable improvement is the shape correction in the main precipitant structure. This structure is correctly positioned in the NWP forecast, but the shape of the observed storm is not well-reproduced. The shift-vector modification corrects this problem and it also conduct to a better simulation of the pattern of the observed storm. Regarding the modification as function of forecast length, Fig. 4 shows that this model correction's methodology improves during the whole forecast period up to $25 \%$ and beats the persistence even at 
Table 4. Correlation between the blending and observation rainfall field in the first hour (upper) and second hour (lower), where the blending is constructed by the index given in the first row and the threshold written in the second column. Best result for each lead time is marked in bold type.

\begin{tabular}{cccccccccc}
\hline Lead time & Threshold[mm] & Npix & RMS & COR & POD & FAR & CSI & BIAS & TSS \\
\hline \multirow{6}{*}{$+1 \mathrm{~h}$} & 0.1 & 0.50 & 0.51 & 0.45 & 0.43 & 0.47 & 0.49 & 0.51 & 0.44 \\
& 0.2 & 0.51 & 0.51 & 0.46 & 0.43 & 0.47 & 0.49 & 0.51 & 0.44 \\
& 1.0 & 0.53 & 0.52 & 0.49 & 0.46 & 0.46 & 0.52 & 0.53 & 0.46 \\
& 2.5 & 0.53 & 0.52 & 0.51 & 0.48 & 0.48 & 0.54 & 0.55 & 0.48 \\
& 5.0 & 0.53 & 0.53 & 0.50 & 0.47 & 0.49 & 0.54 & 0.54 & 0.49 \\
$+2 \mathrm{~h}$ & 10.0 & 0.57 & 0.56 & 0.52 & 0.48 & 0.53 & 0.55 & $\mathbf{0 . 5 8}$ & 0.50 \\
\hline \multirow{4}{*}{+4} & 0.30 & 0.32 & 0.36 & 0.36 & 0.36 & 0.36 & 0.30 & 0.37 \\
& 0.2 & 0.30 & 0.32 & 0.35 & 0.35 & 0.35 & 0.36 & 0.30 & 0.36 \\
& 1.0 & 0.30 & 0.32 & 0.40 & 0.39 & 0.36 & 0.41 & 0.32 & 0.41 \\
& 2.5 & 0.29 & 0.32 & 0.39 & 0.38 & 0.38 & 0.41 & 0.31 & 0.41 \\
& 5.0 & 0.29 & 0.32 & 0.45 & 0.43 & 0.38 & 0.46 & 0.31 & 0.47 \\
& 10.0 & 0.31 & 0.33 & 0.51 & $\mathbf{0 . 5 2}$ & 0.38 & 0.50 & 0.32 & 0.49 \\
\hline
\end{tabular}

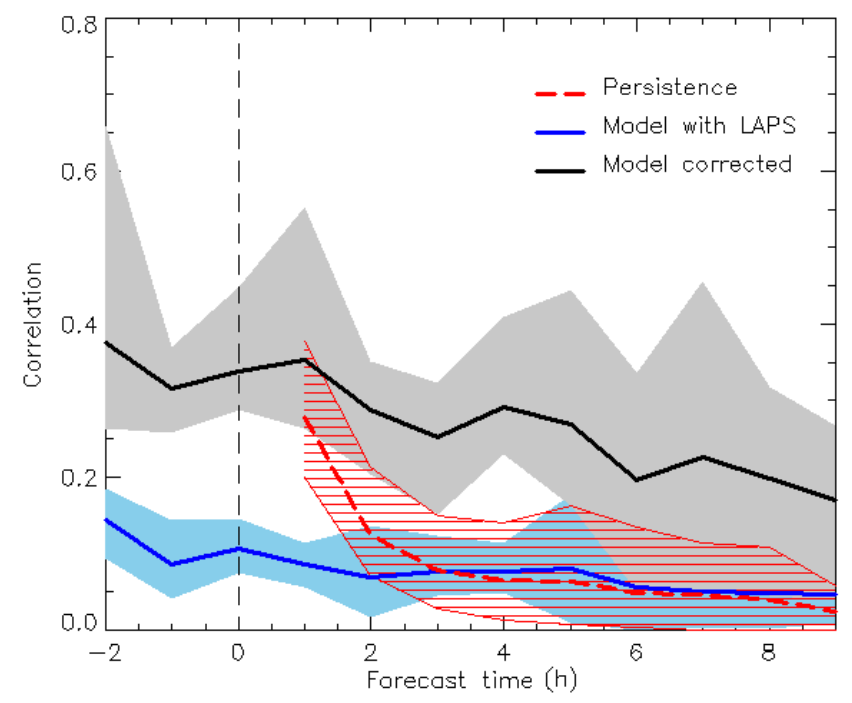

Fig. 4. Correlation of observation with the persistence (red), model (blue) and model corrected (black) as a function of forecast time. The shaded areas represent the range of results whereas the solid line is the mean of the seven case studies.

the first hour. So this ameliorator let us blending the model with the advection forecast in a suitable way.

Once the model has been corrected, the blending technique can be applied. The first step is determining the best threshold and index to compute the weights. For this reason different indexes and thresholds are tested. By analyzing the results for all the case studies (Table 4), it could be concluded that CSI, which is the index selected in Golding (1998), is suitable to compute the blending weights. Nevertheless, the best one for the first hour is the bias, whereas POD is the chosen one for the second hour. However, the most remarkable results are that the higher the precipitation threshold consid-
Table 5. Several Verification indexes for different thresholds for the first hour blending forecast (BLE), Model correction (MCO) and advection of reflectivity field (ADV) plotted in Fig. 5. Best results are marked in bold.

\begin{tabular}{cccccc}
\hline \multirow{2}{*}{ Source } & & \multicolumn{4}{c}{ Threshold } \\
\cline { 3 - 6 } & Score & 0.1 & 0.5 & 1.0 & 5.0 \\
\hline \multirow{4}{*}{ MCO } & COR & 0.43 & 0.41 & 0.39 & 0.12 \\
& TSS & 0.74 & 0.71 & 0.66 & 0.26 \\
& CSI & 0.35 & 0.31 & 0.26 & 0.07 \\
& BIAS & 2.54 & 2.46 & 2.57 & 3.38 \\
& RMSE & 1.48 & 1.49 & 1.50 & 1.38 \\
\hline \multirow{4}{*}{ ADV } & COR & 0.67 & 0.66 & 0.63 & 0.19 \\
& TSS & 0.74 & 0.72 & 0.72 & 0.29 \\
& CSI & $\mathbf{0 . 6 6}$ & $\mathbf{0 . 6 3}$ & $\mathbf{0 . 5 9}$ & 0.11 \\
& BIAS & $\mathbf{0 . 8 9}$ & $\mathbf{0 . 8 9}$ & $\mathbf{0 . 9 7}$ & 2.13 \\
& RMSE & 0.79 & 0.80 & 0.82 & 0.96 \\
\hline \multirow{3}{*}{ BLE } & COR & $\mathbf{0 . 6 9}$ & $\mathbf{0 . 6 8}$ & $\mathbf{0 . 6 6}$ & $\mathbf{0 . 2 0}$ \\
& TSS & $\mathbf{0 . 8 1}$ & $\mathbf{0 . 7 6}$ & $\mathbf{0 . 7 6}$ & $\mathbf{0 . 2 9}$ \\
& CSI & 0.46 & 0.43 & 0.43 & $\mathbf{0 . 1 3}$ \\
& BIAS & 1.97 & 1.74 & 1.58 & $\mathbf{1 . 5 9}$ \\
& RMSE & $\mathbf{0 . 7 2}$ & $\mathbf{0 . 7 3}$ & $\mathbf{0 . 7 4}$ & $\mathbf{0 . 7 8}$ \\
\hline
\end{tabular}

ered, the better weight for blending is obtained. This result could be explained by the fact that high thresholds only take into account the most intense storms, rejecting the low intensity rainfall. Low amounts of precipitation in the model could be related to spurious or residual rainfall. So, neglecting these areas by using high thresholds provides an accurate value to the weights. Another conclusion of this preliminary study of classical blending is that weights vary dynamically with the previous error index giving more representation to advection in the first hour and more importance to NWP 


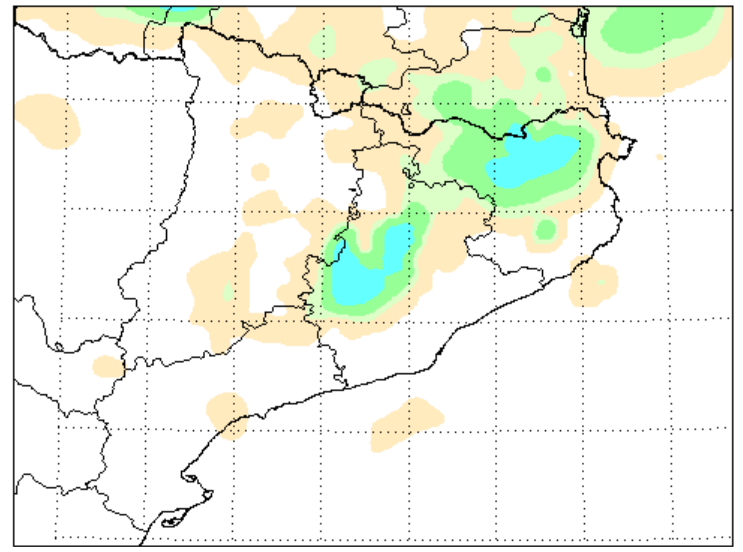

(a) Model corrected

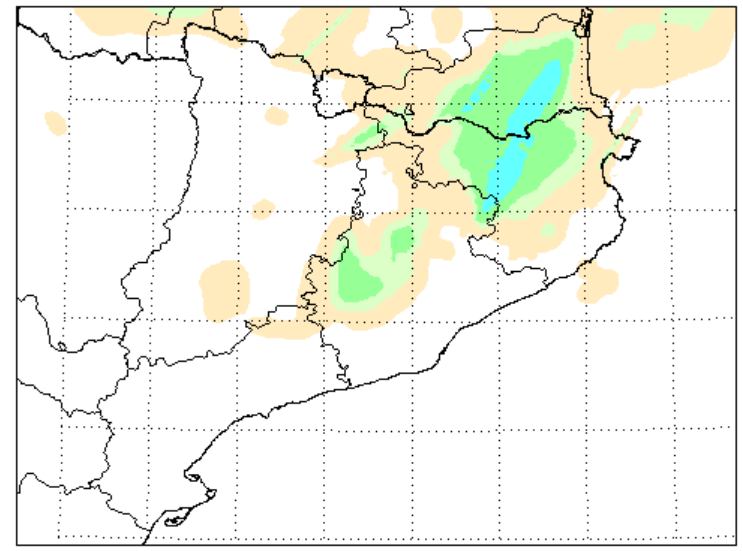

(c) Blending

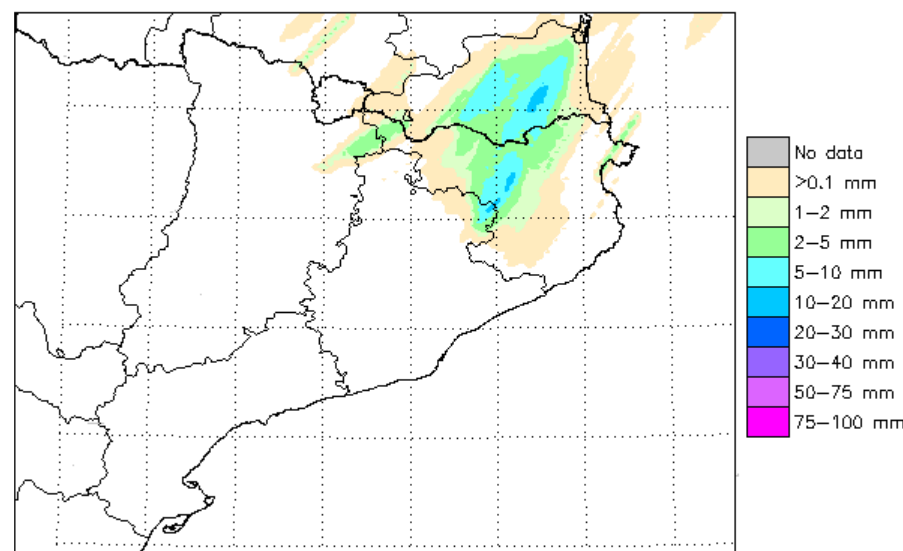

(b) Reflectivity advection

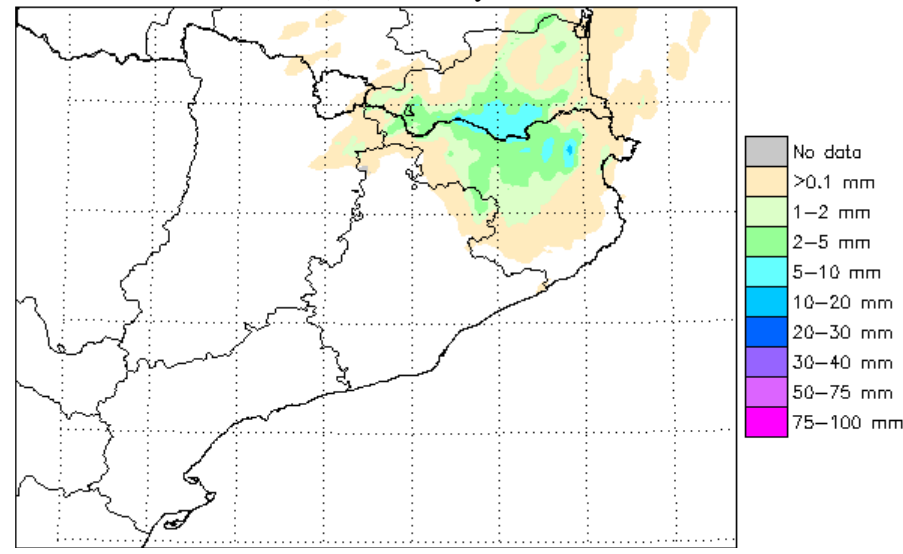

(d) Observation

Fig. 5. An example of 22:00 UTC blending forecast for the next hour (23:00 UTC) of the 14 July 2009 event.

forecasts in the second hour. This fact could be observed in Fig. 7 by comparing both blending techniques, one with the model corrected and another with the model uncorrected. The difference between blending with model corrected and model uncorrected in the first hour is smaller than in the second hour. This is because a heavier weight is given to advection in the first hour but to the model in the second one.

To identify the strong and weak points of this methodology an example is analysed. The example fields plotted (Fig. 5 and 6) shows that introducing information from the model has positive and negative influences. For instance, in the first hour blending rainfall field (Fig. 5c) new areas of rainfall appear where no new rainfall is observed (Fig. 5d). But the rainfall structure is extended to the east side where rainfall is observed too. For the second hour, the blending procedure weakened the rainfall field (Fig. 6c) which really happened as can be observed in the real rainfall field (Fig. 6d). The different statistical indexes (Table 5) show an improvement in correlation and True Skill Score for the blending together with the root mean square error. However, CSI and bias are better in the advection forecasting, but for the threshold higher than $5 \mathrm{~mm}$, the blending beats the advection forecast- ing again. For the second hour a similar behavior is reported (Table 6). The blending gets the best index for correlation and True Skill Score again (and CSI for threshold higher than $1 \mathrm{~mm}$ ). The minimum RMSE is obtained by the model, but with quite similar values than with the blending technique results.

Finally, a comparison of both techniques, spatial and classical blending, and the best result of previous existent forecasting methodologies is presented (Fig. 7) as function of forecast length. The introduction of spatial dependence of weights as function of distance of rainfall cells improves noticeably the first hour blended forecast field (it increases the correlation up to $25 \%$ ). The main objective of this procedure is to reduce the loss of information where no rainfall is extrapolated due to the inexistence of previous radar rainfall observations. There is only rainfall from model in this area, for this reason, the model is modulated in these areas by a quality index. But, where there is rainfall from the advection procedure, both extrapolation and NWP forecast are blended. This approach gives more representation to advection in the first hour than in the classical blending. Furthermore, the new rainfall areas generated by the model are corrected but not 


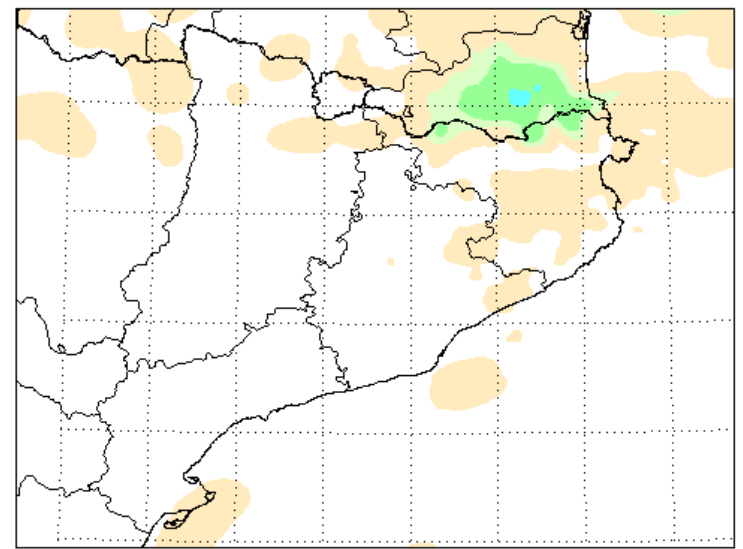

(a) Model corrected

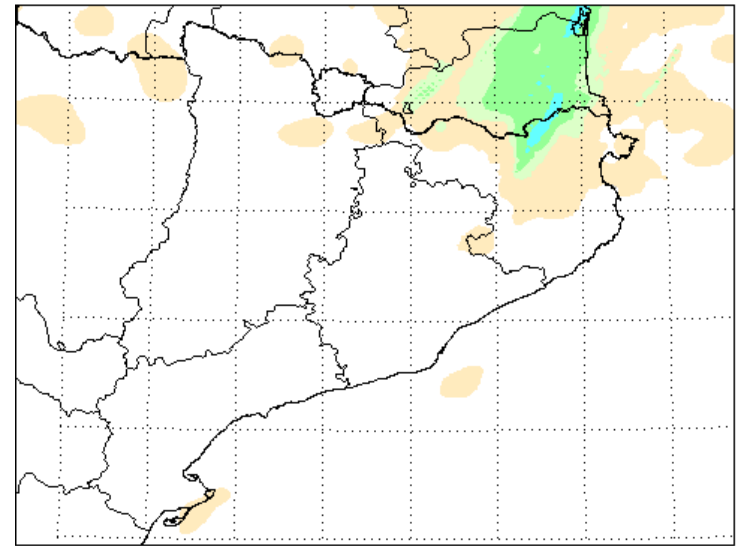

(c) Blending

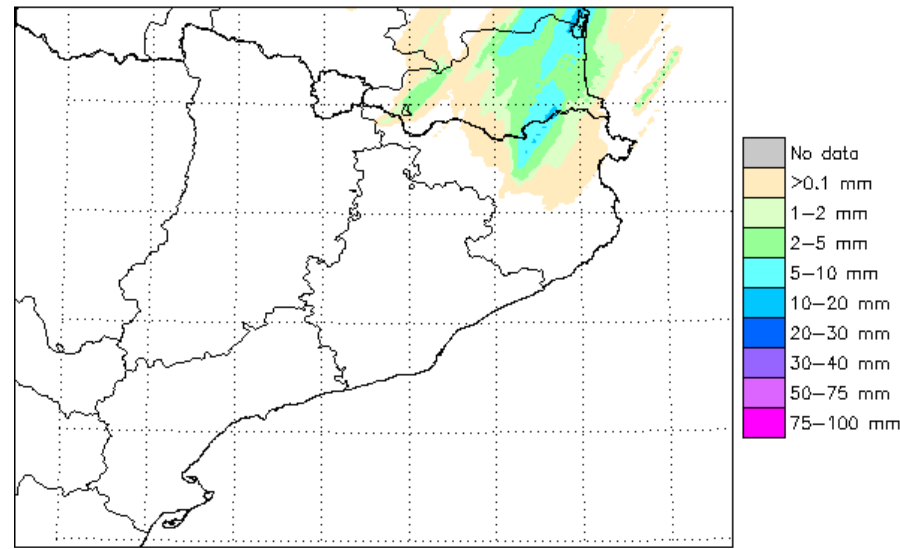

(b) Reflectivity advection

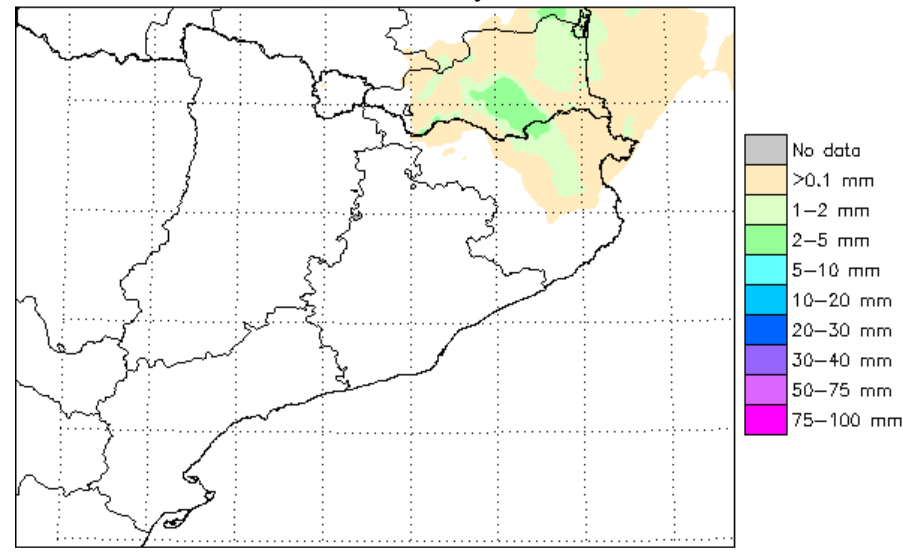

(d) Observation

Fig. 6. An example of 22:00 UTC blending forecast for the second hour (00:00 UTC) of the 14 July 2009 event.

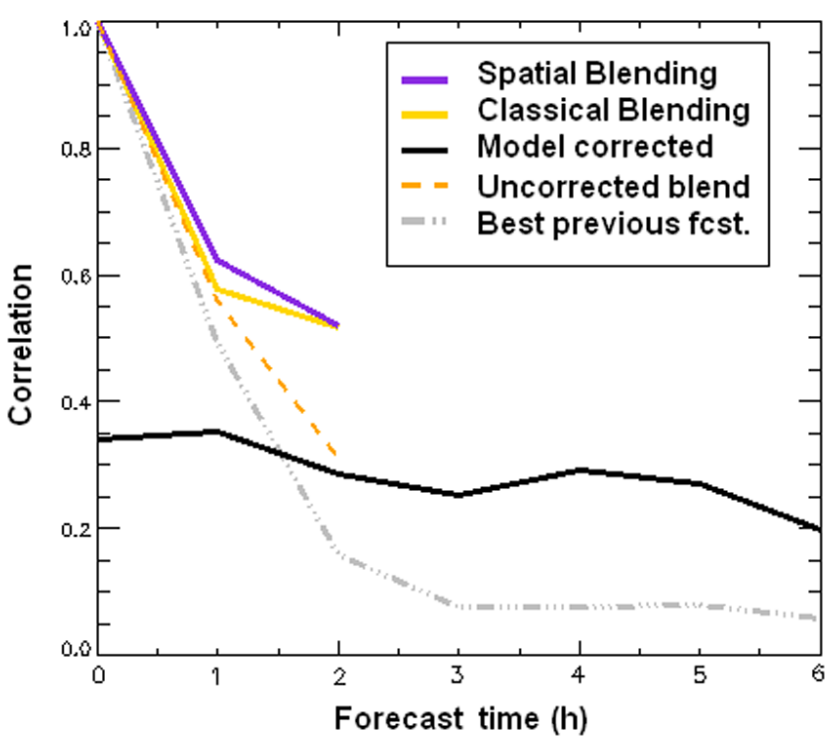

Fig. 7. Correlation of all the methodologies developed in the present work and the best previous one as function of forecast length. weighted. Because of that, this procedure has the ability to better integrate the skill of rainfall location and patterns that are given by the extrapolation of rainfall field with the capacity of generating new precipitation areas from NWP models. Then, the first hour spatial blending field is better than that from classical blending. For the second hour, spatial blending is the best one again. Nevertheless, the correlations for both blending techniques are quite similar. From the third up to the sixth hour, only the model correction is still applied. It is selected because correlation results obtained with this methodology beat those obtained without correction or persistence.

\section{Conclusions}

A blending approach to improve QPF for the first six hours is described in this paper. The work is divided into a previous model correction and the merging of corrected NWP and extrapolation forecasts. So, different conclusions could be extracted from these techniques.

The model used in this paper was simply interpolated by a cubic spline interpolation. This procedure only reduces the 
Table 6. Several Verification indexes for different thresholds for the second hour blending forecast (BLE), Model correction (MCO) and advection of reflectivity field (ADV) plotted in Fig. 6. Best results are marked in bold.

\begin{tabular}{lccccc}
\hline \multirow{2}{*}{ Source } & & \multicolumn{4}{c}{ Threshold } \\
\cline { 3 - 6 } & Score & 0.1 & 0.5 & 1.0 & 5.0 \\
\hline \multirow{4}{*}{ MCO } & COR & 0.60 & 0.56 & 0.47 & 0.00 \\
& TSS & 0.63 & 0.47 & 0.37 & 0.00 \\
& CSI & 0.30 & 0.33 & 0.23 & 0.00 \\
& BIAS & 2.51 & 1.01 & 1.07 & 0.00 \\
& RMSE & $\mathbf{0 . 4 8}$ & $\mathbf{0 . 4 9}$ & $\mathbf{0 . 5 1}$ & $\mathbf{0 . 2 7}$ \\
\hline \multirow{4}{*}{ ADV } & COR & 0.66 & 0.64 & 0.56 & 0.00 \\
& TSS & 0.68 & 0.64 & 0.74 & 0.00 \\
& CSI & $\mathbf{0 . 6 1}$ & $\mathbf{0 . 5 5}$ & 0.43 & 0.00 \\
& BIAS & $\mathbf{0 . 8 2}$ & $\mathbf{0 . 8 5}$ & $\mathbf{1 . 5 2}$ & 0.00 \\
& RMSE & 0.87 & 0.88 & 0.93 & 0.91 \\
\hline \multirow{4}{*}{ BLE } & COR & $\mathbf{0 . 7 4}$ & $\mathbf{0 . 7 1}$ & $\mathbf{0 . 6 2}$ & 0.00 \\
& TSS & $\mathbf{0 . 7 8}$ & $\mathbf{0 . 6 8}$ & $\mathbf{0 . 7 5}$ & 0.00 \\
& CSI & 0.47 & 0.54 & $\mathbf{0 . 4 4}$ & 0.00 \\
& BIAS & 1.73 & 0.97 & 1.53 & 0.00 \\
& RMSE & 0.51 & 0.53 & 0.57 & 0.34 \\
\hline
\end{tabular}

grid resolution, but maintains the real resolution simulated by the model. The proposed shift-vector model correction has shown the ability to improve the rainfall position as well as precipitation pattern structures. This fact ensures the model could be properly used in a grid of $2 \times 2 \mathrm{~km}^{2}$.

Once position errors of the model were corrected (from model simulation) and shape errors (from real scale solved) two blending techniques have been applied. Both of them are suitable approaches to improve QPF in the first hours. The first approach, called classical blending, is based on existing techniques. It is used not only to test the best index and threshold, but also to quantify the real improvement introduced by the second technique (spatial blending).

From the index and threshold test it could be concluded that CSI, which is the index used in similar studies, is suitable to compute the blending weights. The best scores are obtained by bias in the first hour and POD for the second hour. However, compared to CSI, POD produces worse results for the first hour and bias for the second. Regarding the thresholds, the most remarkable result is that the higher the precipitation threshold, the better weight is obtained for blending.

Regarding the spatial blending, it has been observed that the introduction weights as distance function previous rainfall structures improve mainly the first hour because of maintaining the new precipitation areas coming from the model.

To sum up, this work has shown the blending technique (especially the spatial one) as a suitable approach to improve the QPF in the first hours. But a correct positioning of rainfall from the model is required. For this reason, an appropriate
Table A1. Matrix showing the frequencies of predicted and/or observed events determined by threshold $(T)$. This matix is called contingency table.

\begin{tabular}{cccc}
\hline & & \multicolumn{2}{c}{ Predicted } \\
\hline \multirow{4}{*}{ Observed } & \begin{tabular}{c} 
rain $<T$ \\
\cline { 3 - 3 }
\end{tabular} & zeros $(\mathrm{Z})$ & fain $>T$ \\
& rain $>T$ & misses $(\mathrm{M})$ & hits $(\mathrm{H})$ \\
\hline
\end{tabular}

and sound procedure to correct the phase errors of the model (both position and shape error) has been developed too by means of combining several existing techniques. Combining spatial blending and model correction, a proper approach is obtained to improve remarkably the QPF from the first up to the sixth hour.

\section{Appendix A}

In this appendix section all the categorical, or conditional, statistics and qualitative indexes used in this article are formulated in the first subsection. The second one shows the transformation of these indexes into their standard form.

\section{A1 General indexes}

$$
\begin{aligned}
& \text { - } \mathrm{CSI}=\frac{H}{H+F A+M} \in[0,1] \\
& \text { - POD }=\frac{H}{H+M} \in[0,1] \\
& \text { - FAR }=\frac{F A}{H+F A} \in[0,1] \\
& \text { - TSS }=\frac{Z \cdot H-F A \cdot M}{(Z+F A) \cdot(M+H)} \in[-1,1] \\
& \text { - bias }=\frac{H+F A}{H+M} \in[0, \infty] \\
& \text { - RMSE }=\sqrt{\frac{\sum_{i=0}^{n}\left(F_{i}-O_{i}\right)^{2}}{n}} \in[0, \infty] \\
& \text { - \# Pixels }=F A+H \in[0,33970] \\
& \text { - correlation }=\frac{\sum_{i=0}^{n}\left(F_{i} \cdot O_{i}\right)}{\sqrt{\mathbf{F}^{2} \cdot \mathbf{O}^{2}}} \in[0,1]
\end{aligned}
$$

The variables $H, F A, M$ and $Z$ are defined in the contingency table (Table A1), whereas $F_{i}$ is the forecast field at position $i$ and $O_{i}$ is the observation at the same position. Finally, $n$ represents the total number of observations and forecasts over the threshold $T$, so $n=M+H+F A$. 


\section{A2 Transformation formulation}

The RMSE and \# pixels are not modified due to their range. The bias has the same range, however the best forecast is the value 1 . For this reason a logarithmic transformation is applied to the bias. The final transformation (Eq. A9) is:

$v=|\log \operatorname{bias}|$

All the other indexes are transformed by the following equation (Eq. A10):

$v=\frac{1-\text { index }}{\text { index }}$

Only the TSS and FAR need a previous change. One is added to TSS and then is divided by 2 . $\mathrm{TSS}^{m}=(\mathrm{TSS}+1) / 2$. FAR is inverted as $\mathrm{FAR}^{m}=|\mathrm{FAR}-1|$.

Acknowledgements. This research is supported by the NOWCASTING project (Department of the Environment and Housing of the Generalitat of Catalonia), the Seventh Framework Programme European Commission IMPRINTS project (no. 226555), the European Project FLASH, FP6-2005-Global-4 (no. 036852) and the COST-731 concerted Action (Rossa et al., 2010). The authors want to thank Manel Ceperuelo for all the previous work carried out during the first two years of the NOWCASTING project.

Edited by: A. Mugnai

Reviewed by: G. Boni and two other anonymous referees

\section{References}

Albers, S., McGinley, J., Birkenheuer, D., and Smart, J.: The Local Analysis and Prediction System (LAPS): Analyses of clouds, precipitation, and temperature, Weather and Forecasting, 11, 273-287, 1996.

Bech, J., Rigo, T., Pineda, N., Segalà, S., Vilaclara, E., SánchezDiezma, R., Sempere, D., and Velasco, E.: Implementation of the EHIMI software package in the weather radar operational chain of the catalan meteorological service, in: Proceedings 32 nd International Conference on Radar Meteorology, Alburquerque, NM, USA, 2005.

Bech, J., Codina, B., and Lorente, J.: Forecasting weather radar propagation conditions, Meteor. Atmos. Phys., 96, 229-243, 2007.

Bellon, A. and Kilambi, A.: Updates to the McGill RAPID(Radar Data Analysis, Processing and Interative Display) system, in: International Conference on Radar Meteorology, 29 th, Montreal, Canada, pp. 121-124, 1999.

Berenguer, M., Corral, C., Sánchez-Diezma, R., and SempereTorres, D.: Hydrological validation of a radar-based nowcasting technique, J. Hydrometeorol., 6, 532-549, 2005.

Berenguer, M., Sempere-Torres, D., Corral, C., and SánchezDiezma, R.: A fuzzy logic technique for identifying nonprecipitating echoes in radar scans, J. Atmos. Oceanic Technol., 23, 1157-1180, 2006.

Bowler, N., Pierce, C., and Seed, A.: STEPS: A probabilistic precipitation forecasting scheme which merges an extrapolation nowcast with downscaled NWP, Q. J. Roy. Meteorol. Soc., 132, 2127-2155, 2006.
Brewster, K.: Phase-correcting data assimilation and application to storm-scale numerical weather prediction. Part I: Method description and simulation testing, Mon. Weather Rev., 131, 480 492, 2003a.

Brewster, K.: Phase-correcting data assimilation and application to storm-scale numerical weather prediction. Part II: Application to a severe storm outbreak, Mon. Weather Rev., 131, 493-507, 2003b.

Casati, B., Ross, G., and Stephenson, D.: A new intensity-scale approach for the verification of spatial precipitation forecasts, Meteorological Applications, 11, 141-154, 2004.

Casati, B., Wilson, L., Stephenson, D., Nurmi, P., Ghelli, A., Pocernich, M., Damrath, U., Ebert, E., Brown, B., and Mason, S.: Forecast verification: current status and future directions, Meteorological Applications, 15, 3-18, 2008.

Côté, J., Gravel, S., Méthot, A., Patoine, A., Roch, M., and Staniforth, A.: The operational CMC-MRB global environmental multiscale (GEM) model. Part I: Design considerations and formulation, Mon. Weather Rev., 126, 1373-1395, 1998.

Delrieu, G., Creutin, J., and Andrieu, H.: Simulation of radar mountain returns using a digitized terrain model, J. Atmos. Oceanic Technol., 12, 1038-1049, 1995.

Denis, B., Côté, J., and Laprise, R.: Spectral decomposition of twodimensional atmospheric fields on limited-area domains using the discrete cosine transform (DCT), Mon. Weather Rev., 130, 1812-1829, 2002.

Ebert, E. and Seed, A.: Use of radar rainfall estimates to evaluate mesoscale model forecasts of convective rainfall, in: Sixth International Symposium on Hydrological Applications of Weather Radar, pp. 271-273, Melbourne, Australia, 2004.

Fox, N., Wilson, J., and Boulder, C.: Very short period quantitative precipitation forecasting, Atmos. Sci. Lett., 6, 7-11, 2005.

Germann, U. and Zawadzki, I.: Scale-dependence of the predictability of precipitation from continental radar images. Part I: Description of the methodology, Mon. Weather Rev., 130, 2859 2873, 2002.

Golding, B.: Nimrod: A system for generating automated very short range forecasts, Meteorological Applications, 5, 1-16, 1998.

Grell, G., Dudhia, J., and Stauffer, D.: A description of the fifthgeneration Penn State/NCAR Mesoscale Model (MM5), NCAR Technical Note, 398, 122, 1994.

Johnson, J., MacKeen, P., Witt, A., Mitchell, E., Stumpf, G., Eilts, M., and Thomas, K.: The storm cell identification and tracking algorithm: An enhanced WSR-88D algorithm, Weather and Forecasting, 13, 263-276, 1998.

Jones, C. and Macpherson, B.: A latent heat nudging scheme for the assimilation of precipitation data into an operational mesoscale model, Meteorological Applications, 4, 269-277, 1997.

Lawson, W. and Hansen, J.: Alignment error models and ensemblebased data assimilation, Mon. Weather Rev., 133, 1687-1709, 2005.

Lee, G., Daegu, S., Zawadzki, I., Wilson, J., Xu, M., Kilambi, A., and Pinto, J.: Improved precipitation nowcasting: Model errors and their correction in operational NWPs at different scales, in: 34th Conference on Radar Meteorology, 2009.

Li, P. and Lai, E.: Short-range quantitative precipitation forecasting in Hong Kong, J. Hydrol., 288, 189-209, 2004.

Lin, C., Vasic, S., Kilambi, A., Turner, B., and Zawadzki, I.: Precipitation forecast skill of numerical weather prediction mod- 
els and radar nowcasts, Geophys. Res. Lett., 32, L14801, doi:10.1029/2005GL023451, 2005.

Mariano, A.: Contour analysis: A new approach for melding geophysical fields, J. Atmos. Oceanic Technol., 7, 285-295, 1990.

Marshall, J. and Palmer, W.: The distribution of raindrops with size, J. Atmos. Sci., 5, 165-166, 1948.

McGinley, J. and Smart, J.: On providing a cloud-balanced initial condition for diabatic initialization, in: Conference on weather analysis and forecasting, vol. 18, pp. 40-44, 2001.

Pierce, C., Hardaker, P., Collier, C., and Haggett, C.: GANDOLF: a system for generating automated nowcasts of convective precipitation, Meteorological Applications, 7, 341-360, 2001.

Pierce, C., Bowler, N., Seed, A., Jones, A., Jones, D., and Moore, R.: Use of a stochastic precipitation nowcast scheme for fluvial flood forecasting and warning, Atmos. Sci. Lett., 6, 78-83, 2005.

Prohom, M. and Herrero, M.: Towards the creation of a climatic database for Catalonia (18th to 21st centuries), Tethys: Revista del temps i el clima de la Mediterrània occidental, 5, 2009.

Rigo, T. and Llasat, M. C.: A methodology for the classification of convective structures using meteorological radar: Application to heavy rainfall events on the Mediterranean coast of the Iberian Peninsula, Nat. Hazards Earth Syst. Sci., 4, 59-68, doi:10.5194/nhess-4-59-2004, 2004.

Rigo, T. and Llasat, M.: Analysis of mesoscale convective systems in Catalonia using meteorological radar for the period 19962000, Atmos. Res., 83, 458-472, 2007.

Rossa, A., Haase, G., Keil, C., Alberoni, P., Ballard, S., Bech, J., Germann, U., Pfeifer, M., and Salonen, K.: Propagation of uncertainty from observing systems into NWP: COST-731 Working Group 1, Atmos. Sci. Lett., 11, 145-152, 2010.

Sánchez-Diezma, R., Sempere-Torres, D., Delrieu, G., and Zawadki, I.: An improved methodology for ground clutter substitution based on a pre-classification of precipitation types. 30th Internat, in: Conf. on Radar Meteor., Munich, Germany, Amer. Meteor. Soc, pp. 271-273, 2001.
Sánchez-Diezma, R., Sempere-Torres, D., Bech, J., and Velasco, E.: Developement of a hydrometeorological flood warning system (EHIMI) based on radar data, in: Second European Conference on Radar Meteorology, Delft, Netherlands, 2002.

Sardeshmukh, P. and Hoskins, B.: Spatial smoothing on the sphere, Mon. Weather Rev., 112, 2524-2529, 1984.

Schmid, W., Mecklenburg, S., and Joss, J.: Short-term risk forecasts of heavy rainfall., Water science and technology: a journal of the International Association on Water Pollution Research, 45, 121125, 2002.

Schultz, P. and Albers, S.: The use of three-dimensional analyses of cloud attributes for diabatic initialization of mesoscale models, in: Conference on weather analysis and forecasting, vol. 18, pp. 122-124, 2001.

Seed, A.: A dynamic and spatial scaling approach to advection forecasting, J. Appl. Meteorol., 42, 381-388, 2003.

Sempere-Torres, D., Sánchez-Diezma, R., Berenguer, M., Pascual, R., and Zawadzki, I.: Improving radar rainfall measurement stability using mountain returns in real time, in: 31th International Conference on Radar Meteorology, 2003.

Staniforth, A. and Côté, J.: Semi-Lagrangian integration schemes for atmospheric modelsA review, Mon. Weather Rev., 119, 2206-2223, 1991.

Thiebaux, H., Julian, P., and DiMego, G.: Areal versus collocation data quality control. Preprints, in: Int. Symp. on Assimilation of Observations in Meteorology and Oceanography, pp. 255-260, 1990.

Thunis, P. and Bornstein, R.: Hierarchy of mesoscale flow assumptions and equations, J. Atmos. Sci., 53, 380-397, 1996.

Venugopal, V., Foufoula-Georgiou, E., and Sapozhnikov, V.: Evidence of dynamic scaling in space-time rainfall, J. Geophys. Res., 104, 31599-31610, 1999. 